\title{
Outcomes versus intentions: On the nature of fair behavior and its development with age
}

\author{
Matthias Sutter \\ University of Innsbruck, Department of Public Economics, Universitaetsstrasse 15, A-6020 Innsbruck, Austria
}

Received 15 May 2006; received in revised form 17 September 2006; accepted 20 September 2006

Available online 13 November 2006

\begin{abstract}
Economic decisions depend on both actual outcomes as well as perceived intentions. In this paper, we examine whether and how the relative importance of outcomes or intentions for economic decisions develops with age. We report the results of ultimatum games with children, teens and university students. We find that children and teens react systematically to perceived intentions, like university students do. However, children and teens reject unequal offers much more often than university students, indicating that outcomes are relatively more important than intentions for younger subjects. Hence, the relative importance of intentions increases with age.

(c) 2006 Elsevier B.V. All rights reserved.
\end{abstract}

\section{JEL classification: C91}

PsycINFO classification: 2800

Keywords: Fairness; Intentions; Ultimatum game; Children; Age

\section{Introduction}

Whereas the standard economic approach would judge an action only by its outcome (or utility), recent economic research has stressed the importance of intentions for judging actions. In fact, the perceived intentions of an interaction partner are often considered as equally important as the actual outcome of the partner's action (Charness \& Levine, 2003).

E-mail address: matthias.sutter@uibk.ac.at 
To illustrate the significance of intentions, Falk, Fehr, and Fischbacher (2003) and Nelson (2002) have shown that identical offers in an ultimatum game generate different rejection rates, depending on the available alternative offers. A particular unequal distribution is much more often rejected if the proposer could have offered a more equitable distribution as the alternative than if the only available alternative was an even more unequal distribution. Burnham, McCabe, and Smith (2002) and McCabe, Rigdon, and Smith (2003) have examined - and confirmed - the importance of intentions in trust games. Rather than manipulating the available alternatives, Burnham et al. (2002) have manipulated the framing of the trust game by denoting the counterpart either "partner" or "opponent". Indeed, the "partner"-treatment elicits much more trust and reciprocity, probably because intentions of "partners" are perceived to be friendlier than those of "opponents". McCabe et al. (2003) have manipulated the outside options of the first mover in a trust game, showing that trust and trustworthiness are higher when the first mover has positive opportunity costs of being cooperative than when opportunity costs are zero. In the former case, a cooperative move signals good intentions whereas in the latter case the second mover cannot infer the benevolence of the first mover's intentions.

In this paper, we address the question whether the relative importance of outcomes versus intentions changes with the age of the subjects. Using an experimental ultimatum game with a restricted set of offers, we study whether the influence of outcomes and intentions develops from childhood to early adult age. For this purpose we ran an experiment with children (7-10 years old), teens (11-15 years) and university students (19-33 years) as subjects.

Both Murnighan and Saxon (1998) and Harbaugh, Krause, and Liday (2002) have previously studied the behavior of children in ultimatum games. Possibly due to differences in the experimental protocol concerning anonymity and real financial consequences, they have arrived at opposite results concerning proposer behavior. Younger children make larger offers than older ones in the study of Murnighan and Saxon (1998), but Harbaugh et al. (2002) find the opposite result. With respect to responder behavior, both studies show that younger children accept relatively smaller offers more often. Since responders, however, faced only one single offer and since the set of alternative offers was not restricted in the way we will do it, both studies remain silent on the relative importance of outcomes and proposers' intentions for responders' decisions.

Given that numerous experimental studies with student participants have led to new approaches in modeling economic decision-making and the influence of outcomes and intentions, ${ }^{1}$ whether these models are suitable for describing and predicting behavior of subjects who are not students in their early twenties should be considered a relevant issue for economics.

In fact, evidence from developmental psychology suggests that behavior that is relevant for economic situations is prone to substantial changes in the span of a lifetime, particularly in the phase from childhood to (early) adulthood (Kail \& Cavanaugh, 2004). For instance, Eisenberg and Fabes (1998) show that prosocial behavior is increasing from

\footnotetext{
${ }^{1}$ Concerning the interplay of outcomes and intentions in bargaining situations, many of the recent models on social preferences have concentrated either on outcomes or intentions (see, e.g., Bolton \& Ockenfels, 2000; Fehr \& Schmidt, 1999; on outcome-based models, or Dufwenberg \& Kirchsteiger, 2004; Rabin, 1993; on intentions-based models). Only a few models incorporate both outcomes and intentions (see Charness \& Rabin, 2002; Falk \& Fischbacher, 2006).
} 
childhood to adulthood. ${ }^{2}$ Concerning the relative importance of outcomes and intentions, the literature on the theory of the mind (Baron-Cohen, 1995) suggests that children only gradually learn to attribute intentions to other subjects' acts in the course of socialization. This insight dates back, in general, to Piaget (1932). In his research program on the development of moral judgment, he has found that younger children (up to about 10 to 12 years) differ from older ones and adults in that they tend to give more weight to the amount of damage caused by a wrongful act than to the actor's intentions. Of course, subsequent research has shown that children learn to distinguish intentional from unintentional acts already by the age of 3-4 years (Feinfield, Lee, Flavell, Green, \& Flavell, 1999; Flavell, 1999), but that does not preclude the possibility that the relative weight of outcomes versus intentions may still shift with age in favor of intentions, as implied by the findings of Piaget (1932). Consequently, we expect younger subjects to attach more weight to the pure outcome of an act than to the intentions behind it. This hypothesis is tested in an experiment. Section 2 describes the experimental design, and Section 3 is devoted to the experimental procedure. The experimental results are presented in Section 4 , and Section 5 concludes.

\section{Experimental design}

Each participant in our experiment plays four different mini-ultimatum games. The structure of these games is shown in Table 1. In each game, the proposer can choose between two different allocations of 10 experimental points. There is always one identical default allocation, which allocates 8 points to the proposer and 2 points to the responder. Games differ with respect to the available alternative, which allocates $a$ points to the proposer and $10-a$ points to the responder, where $a \in\{10,8,5,2\}$.

We use the strategy method, where in each game the responder has to indicate whether to accept or reject the default $(8 / 2)$ and the alternative $(a / 10-a)$. Acceptance (of the alternative actually chosen by the proposer) leads to a payoff distribution according to the proposer's allocation. Rejection implies zero payoffs for both players in the particular game. Since the behavior of proposers is less important for our research question, this paper focuses predominantly on the responders' behavior.

Even though the default is identical in all games, we expect the following order of rejection rates, where $R[8 / a]$ denotes the rejection rate in Game $[8 / a]:^{3}$

$$
R[8 / 5]>R[8 / 2]>R[8 / 8]>R[8 / 10] .
$$

The highest rejection rates of the default are to be expected in Game [8/5], because choosing the default $(8 / 2)$ instead of $(5 / 5)$ will almost surely be perceived as an intentionally unfriendly act. Offering the default in Game [8/2] - instead of choosing the alternative with (2/8) - should yield lower rejection rates than in Game [8/5], because in Game [8/2],

\footnotetext{
${ }^{2}$ The term prosocial behavior captures, among others, trust, trustworthiness, reciprocity, fairness-concerns, or altruism. These behavioral dispositions have been recognized in the economics literature as important elements for smooth and efficient economic exchanges, for instance when complete contracts are not feasible or unavailable (Camerer, 2003).

${ }^{3}$ For an encompassing discussion concerning the predictions of different fairness models (Bolton \& Ockenfels, 2000; Dufwenberg \& Kirchsteiger, 2004; Fehr \& Schmidt, 1999; or Rabin, 1993) for responder behavior in the four mini-ultimatum games see Section 3 of Falk et al. (2003).
} 
Table 1

The four mini-ultimatum games

\begin{tabular}{lll}
\hline Label & (Proposer/responder) & \\
\cline { 2 - 3 } & Default & Alternative \\
\hline Game $[8 / 10]$ & $8 / 2$ & $10 / 0$ \\
Game $[8 / 8]$ & $8 / 2$ & $8 / 2$ \\
Game $[8 / 5]$ & $8 / 2$ & $5 / 5$ \\
Game $[8 / 2]$ & $8 / 2$ & $2 / 8$ \\
\hline
\end{tabular}

the proposer can only choose between two equally unequal distributions, one to his advantage $(8 / 2)$, and one to his disadvantage $(2 / 8) .{ }^{4}$ Rejection rates in Game $[8 / 8]$ are likely to be lower than in Game [8/2], because the responder can not attribute any intention to the proposer in Game [8/8]. Finally, we expect the lowest rejection rate of the default in Game [8/ $10]$, because the alternative with $(10 / 0)$ is for the responder even worse than the default with $(8 / 2)$.

\section{Experimental procedure}

The experiment was run in July 2003 with a total of 200 participants from three different age groups. We had 54 children of age 7-10 years (mean 9.2 years), 78 teens from 11 to 15 years (mean 12.1 years), and 68 university students from 19 to 33 years (mean 24.6 years). The groups of children and teens were recruited from a large summer camp for kids near Innsbruck. University students were drawn from the e-mail list of experimental participants at the University of Innsbruck. All experimental sessions were run as a paper and pen experiment.

At the beginning of each session, subjects were assigned to different rooms that were close to each other. Subjects in each room were assigned the same role, either of proposer or responder, for the whole experiment. However, the specific role was only announced after the explanation of the experimental instructions, which are reprinted in the Appendix. Due to several no-shows, we do not have the same number of proposers and responders in the groups of children ( 28 proposers and 26 responders) and teens ( 35 proposers and 43 responders), ${ }^{5}$ but we have 34 proposers and 34 responders in the group of university students.

Instructions were read out aloud and subjects were given plenty of time to ask questions. In the groups of children and teens we explained the determination of outcomes very

\footnotetext{
${ }^{4}$ One might argue (like Bolton \& Ockenfels, 2005) that the rejection rate of the default in Game [8/2] should be higher than in Game [8/5]. The intuition for this claim would be that offering the responder 2 units of money is less kind when the alternative would pay 8 (in Game [8/2]) than when the alternative would pay 5 (in Game [8/5]). This kind of intuition is rooted in a pure consequentialist point of view that seems to ignore the distributional consequences of the different feasible allocations in Games [8/5] and [8/2], which of course should matter for ascribed intentions. Actually, Bolton and Ockenfels (2005) do not find higher rejection rates in Game [8/2] than in Game [8/5], which leads them to conclude that only a measure that combines relative payoff comparisons with a reference point conditioned on feasible actions provides a first approximation to their data.

${ }^{5}$ For determining payments of proposers (responders) who were not matched with a real responder (proposer), we randomly drew a matched responder (proposer) whose decisions were then used twice.
} 
carefully by publicly demonstrating how to determine all possible outcomes of the example included in the instructions. After that we asked each child or teenager whether she/he had any remaining questions. In sum, the explanation of the experiment took about 25 min in the groups of children and teens, but only about $10 \mathrm{~min}$ with university students.

The decision-making part itself took between 15 and $20 \mathrm{~min}$ in each age group. The four ultimatum games were played in random order and with different pairs of proposers and responders in each game. Subjects, however, were informed that the other person would also be from the same age group. At the beginning of the decision-making part, each subject received a sealed envelope with a decision card for the first game in it. The subject had to open the envelope, mark her decision on the card and reinsert it into the envelope. Only after this was completed would the subject receive the second envelope for the second game, and so on until the end of the fourth game. Subjects did not receive feedback about the outcome of any game until the end of the experiment in order to avoid income effects and the possibility that current decisions were influenced by an opponent's previous decisions. All four games were paid out at the end. The exchange rate of points into Euros was $0.2 €$ per point for children and teens, and $0.3 €$ per point for university students.

\section{Experimental results}

In Fig. 1, we present the relative frequency of proposers choosing the default in those games in which the available alternative is different from the default. The default is most often chosen in Game [8/10], and least often in Game [8/5]. Checking for differences in proposer behavior across age groups for a given game, we find that teens choose the default significantly less often than university students in Games $[8 / 2]$ and $[8 / 5]\left(p<0.05 ; \chi^{2}\right.$-test). All other differences are insignificant, meaning that proposers of different age groups behave rather similarly. Checking for differences in the frequency of choosing the default across games, but within a given age group, we find in each single age group that the frequency of choosing the default is significantly lower in Game [8/5] than in Games [8/10] or

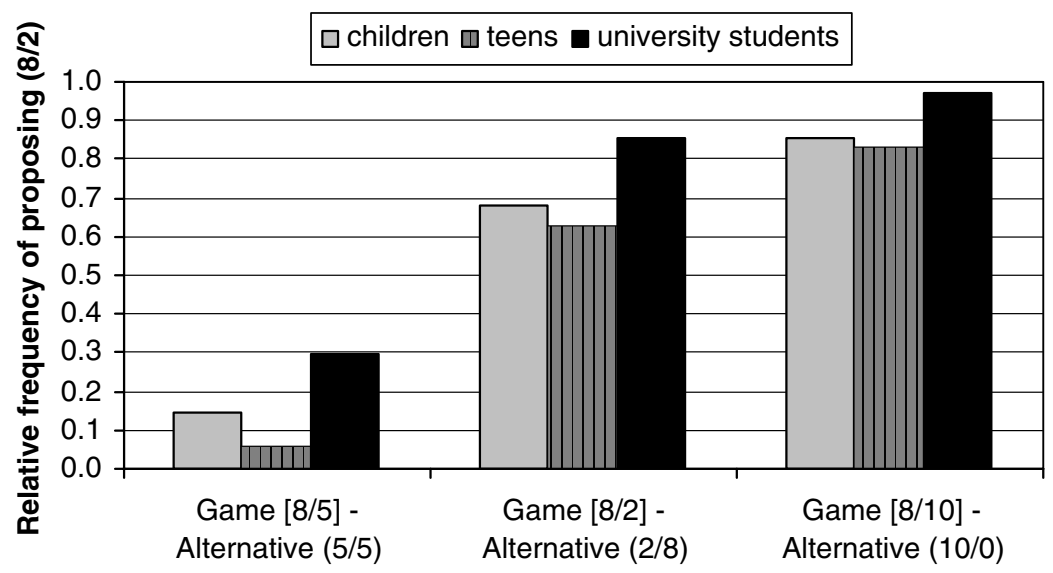

Fig. 1. Relative frequency of proposing the default allocation $(8 / 2)$. 


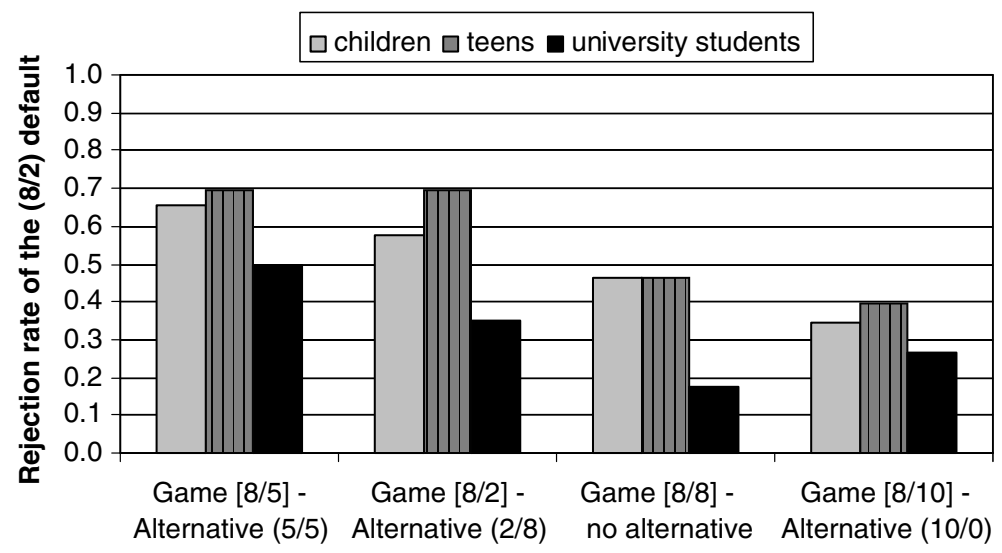

Fig. 2. Relative frequency of rejecting the default allocation (8/2).

$[8 / 2](p<0.05 ;$ McNemar change tests). However, there is no significant difference between Games [8/10] and [8/2].

Responders' rejection rates of the default allocation are shown in Fig. 2. They are significantly different across the four games in each single age group $(p<0.01$; Cochran $Q$ tests). The order of rejection rates fits our expectations almost perfectly, with only a single exception in the student-group. Rejection rates of the default are highest in Game [8/5] in all groups, ranging from $50 \%$ (students) to $70 \%$ (teens). In the groups of children and teens, rejection rates are lowest in Game [8/10], as expected, with 35\% for children and $40 \%$ for teens. University students, however, have the lowest rejection rates in Game [8/ 8]. It is noteworthy that even in the latter game, where the proposer has no choice at all, $18 \%$ of university students, $46 \%$ of children and $47 \%$ of teens reject the allocation $(8 / 2)$. This indicates a rather widespread prevalence of pure aversion against inequitable outcomes, irrespective of the proposer's intentions.

Note that rejection rates in a given game do not differ significantly between children and teens. However, in any game the default (8/2) is more often rejected in the younger age groups of children and teens than in the age group of students. The differences are most pronounced in Games [8/8] and [8/2] where only unequal offers are available to the proposer. In these two games, rejection rates of both children and teens are significantly higher than the corresponding rejection rates of students ( $p<0.05, \chi^{2}$-tests), showing that younger subjects have a stronger aversion to unequal outcomes.

From Fig. 3, we can see that younger subjects reject even favorable, but unequal, offers more often than university students. Children and teen responders reject the advantageous alternative (2/8) in Game [8/2] in $23 \%$ and $28 \%$ of cases, respectively, which is significantly higher than the student rejection rate of $3 \%\left(p<0.05, \chi^{2}\right.$-tests). This indicates that an unequal outcome is more important for the decisions of children and teens than the obviously good intentions of the proposer when he proposes $(2 / 8)$ instead of $(8 / 2)$. Given the consistency of the behavior of children and teens in the other games (see also the individual patterns of behavior below), it seems highly unlikely that confusion might have driven children and teens to react markedly differently than university students in this particular game. It rather seems that in the "intermediate" games (Game [8/2] and Game [8/8]), there 


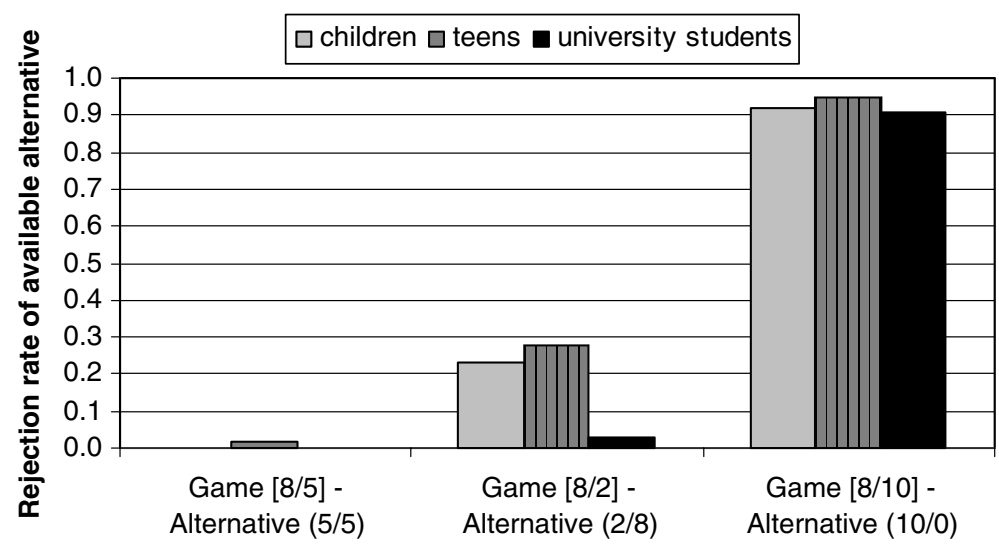

Fig. 3. Relative frequency of rejecting the alternative allocation.

is a shift in the level of rejection rates between students and the younger age groups. This shift is less pronounced in the "extreme" games where the alternative is either completely unfair in Game [8/10] or perfectly fair in Game [8/5]. In fact, there are no significant differences across age groups in Games [8/10] and [8/5] with respect to Fig. 3. Almost all responders reject the allocation (10/0) in Game [8/10], and almost all accept the allocation $(5 / 5)$ in Game [8/5].

So far, we have concentrated on the differences in the aggregate behavior of different age groups. We would like to conclude with a look at individual data. First of all, we examine a responder's monotonicity in her acceptance or rejection decision. A monotonic pattern would mean that a responder accepts all offers larger than or equal to an individual-specific threshold $t$, but rejects all offers smaller than $t$. We find such monotonic patterns for 13 (out of 26) children, 14 (out of 43) teens and 16 (out of 34) students. None of the pairwise differences across age groups is significant. The relatively low frequency of monotonic patterns (compared with about $90 \%$ in standard, unrestricted ultimatum games; Güth, Schmidt, \& Sutter, 2003) is an indication that response behavior is, to a large extent, contingent on the available alternatives, and the absolute amounts at stake are of less importance.

Second, we can analyze individual patterns of acceptance/rejection decisions across the four games. Since each responder had to make two decisions in each game, there are 256 possible patterns in total. It is interesting to note that only 23 patterns can actually be detected, and only five patterns are used by more than five responders. These five patterns are predominant in all age groups, covering between $62 \%$ (students) and $75 \%$ (teens) of all choices. The modal pattern with 10 subjects each in the groups of children as well as students is to accept each offer except for (10/0). This pattern is obviously a monotonic pattern, and it is also the second most frequent in the group of teens (with seven subjects). Nine subjects in the group of teens choose to reject the worse offer in Games [8/10], [8/5], and [8/2], but to accept both (identical) offers in Game [8/8]. ${ }^{6}$ In general, the focal patterns of acceptance/rejection are rather similar across all age groups. The differences in the

\footnotetext{
${ }^{6}$ Note that this pattern has not been classified as monotonic since it rejects (8/2) in Game [8/2], for instance, but accepts it in Game [8/8].
} 
aggregate behavior result from the individuals that show other patterns. Concerning the latter, it becomes evident that children and teens accept less offers than university students do ( $p<0.05$; Kruskal-Wallis test with respect to the sum of accepted offers). The reason for this seems to be a stronger focus on outcomes in the younger age groups.

\section{Conclusion}

Previous experimental research with student participants has shown that rejection rates in ultimatum games with restricted sets of offers depend systematically on the available alternatives (Falk et al., 2003; Nelson, 2002). In this paper, we could confirm these earlier results, but could add the insight that even children and teens show similar patterns of responder behavior in such ultimatum games. Hence, it is both outcomes and intentions that shape the decision-making of children, teens, and university students.

Yet, there are also some developmental changes in the relative weight put on outcomes or perceived intentions. Across all age groups we find that there is a considerable fraction of subjects with a strong aversion to unequal outcomes who then reject unequal offers even if the proposer had no other (or no better) alternative. Our results have shown that this fraction of subjects is significantly larger in the pool of our young subjects (children and teens) than in the pool of students. Children and teens reject unequal offers - both advantageous ones as well as disadvantageous ones - much more often than students do. This reveals that, for younger subjects, equal distributions, i.e., fair outcomes, are relatively more important than the perception of fair intentions. Hence, it seems that the consequentialist practice in economics to define the utility of an action only in terms of its consequences is relatively more appropriate for children and teens than for (university student) adults.

\section{Acknowledgments}

I would like to thank Daniel Read and an anonymous referee for very valuable comments. Christof Fink and his team provided great help for running the experiments with children and teenagers. Olga Mellizo did a great job in language editing. Financial support from the Austrian Science Foundation (FWF Project Nr. 16617) and the Center for Experimental Economics at the University of Innsbruck (sponsored by Raiffeisen-Landesbank Tirol) is gratefully acknowledged.

\section{Appendix A. Experimental instructions}

Welcome to the experiment and thank you very much for your participation. Please do not talk to any other participant until this experiment is finished. If you have any questions, please raise your hand. An experimenter will come to your desk and answer your questions privately.

\section{Two roles in the experiment}

In this experiment there are two possible roles. Person A and Person B. Whether you are a Person A or Person B will be determined later. You will have to draw a sealed envelope in which you will find your role assignment which is fixed for the whole experiment. 
Four decisions by Person A

Person A has to make four decisions throughout the whole experiment. In each decision, Person A must choose between two different options of how to allocate 10 experimental points between herself and a Person B. Please note that in each of these decisions you will be paired with a different person B. Hence, you interact with any other person at most once. Please note also that neither you nor Person B will ever be informed about the identity of the interaction partner.

\section{Sequence of decisions for Person A}

After you have finished reading the instructions, you will receive the first decision card in an envelope. Take out the decision card (below you find an example of such a card), then mark your decision on it and put it back into the envelope. The envelope will them be collected by the experimenter and you will be given the second envelope, ... and so forth until you have made all four decisions. Here is an example of a decision card and how the two options could look like.

Decision card of Person A (example)

\begin{tabular}{lll}
\hline & Please tick one box only \\
\hline Option 1 & 7 points for Person A and 3 points for Person B & $\square$ I choose this option \\
Option 2 & 4 points for Person A and 6 points for Person B & $\square$ I choose this option \\
\hline
\end{tabular}

\section{Decisions of Person B}

For each of the four possible decision cards, Person B must indicate for each of the two options whether she wants to accept that option or not. At that stage of the decision Person B will not be informed about which option has actually been chosen by Person A. Only after Person B has made her decisions for each option on the four different decision cards, will she be informed about the actually chosen options at the end of the experiment (the same goes for Person A who will be informed about Person B's decisions). If Person B has accepted an actually chosen option, then the allocation of points as indicated in this option will be implemented and both Person A and Person B get their points. If Person B has rejected an actually chosen option, both Person A and Person B get nothing (i.e., zero points) for this decision.

\section{Sequence of decisions for Person B}

After you have finished reading the instructions, you will receive the first decision card in an envelope. Take out the decision card (below you find an example of such a card), then mark your decision for each of the two options on it and put it back into the envelope. The envelope will be collected by the experimenter and you will be given the second envelope, .... and so forth until you have made all decisions on the four different decision cards. Here is an example of a decision card and how the two options could look like. 
Decision card of Person B (example)

Please tick one box for each

\begin{tabular}{lll}
\hline Option 1 & 7 points for Person A and 3 points for Person B & $\square$ Accept $\square$ Reject \\
Option 2 & 4 points for Person A and 6 points for Person B & $\square$ Accept $\square$ Reject \\
\hline
\end{tabular}

\section{Payment}

At the end of the experiment you will be paid privately and in cash. The points earned in all four decisions will be added and exchanged into Euro at the following rate: 10 points $=3 €$. (with children and teens it read: 10 points $=2 €)$.

\section{References}

Baron-Cohen, S. (1995). Mindblindness. Cambridge, MA: MIT Press.

Bolton, G. E., \& Ockenfels, A. (2000). ERC - a theory of equity, reciprocity and competition. American Economic Review, 90, 166-193.

Bolton, G. E., \& Ockenfels, A. (2005). A stress test of fairness measures in models of social utility. Economic Theory, 25, 957-982.

Burnham, T. C., McCabe, K. A., \& Smith, V. L. (2002). Friend-or-foe intentionality priming in an extensive form trust game. Journal of Economic Behavior and Organization, 43, 57-73.

Camerer, C. F. (2003). Behavioral game theory. Experiments in strategic interaction. Princeton University Press.

Charness, G., \& Levine, D. I. (2003). The road to hell: An experimental study of intentions. Mimeo.

Charness, G., \& Rabin, M. (2002). Understanding social preferences with simple tests. Quarterly Journal of Economics, 117, 817-869.

Dufwenberg, M., \& Kirchsteiger, G. (2004). A theory of sequential reciprocity. Games and Economic Behavior, 46, 268-298.

Eisenberg, N., \& Fabes, R. A. (1998). Prosocial development. In W. Damon (Ed.), Handbook of child psychology. Wiley.

Falk, A., \& Fischbacher, U. (2006). A theory of reciprocity. Games and Economic Behavior, 54, $293-315$.

Falk, A., Fehr, E., \& Fischbacher, U. (2003). On the nature of fair behavior. Economic Inquiry, 41, 20-26.

Fehr, E., \& Schmidt, K. (1999). A theory of fairness, competition, and cooperation. Quarterly Journal of Economics, 114, 817-868.

Feinfield, K. A., Lee, P. P., Flavell, E. R., Green, F. L., \& Flavell, J. H. (1999). Young children's understanding of intention. Cognitive Development, 14, 463-486.

Flavell, J. H. (1999). Cognitive development: Children's knowledge about the mind. Annual Review of Psychology, $50,21-45$.

Güth, W., Schmidt, C., \& Sutter, M. (2003). Fairness in the mail and opportunism in the internet: A newspaper experiment on ultimatum bargaining. German Economic Review, 4, 243-265.

Harbaugh, W. T., Krause, K., \& Liday Jr., S. G., 2002. Children's bargaining behavior. Working Paper, University of Oregon.

Kail, R. V., \& Cavanaugh, J. C. (2004). Human development: A life-span view. Wadsworth Publishing.

McCabe, K. A., Rigdon, M. L., \& Smith, V. L. (2003). Positive reciprocity and intentions in trust games. Journal of Economic Behavior and Organization, 52, 267-275.

Murnighan, J. K., \& Saxon, M. S. (1998). Ultimatum bargaining by children and adults. Journal of Economic Psychology, 19, 415-445.

Nelson, W. R. Jr., (2002). Equity and intentions: It is thought that counts. Journal of Economic Behavior and Organization, 48, 423-430.

Piaget, J. (1932). The Moral judgment of the child. Free Press.

Rabin, M. (1993). Incorporating fairness into game theory. American Economic Review, 83, 1281-1302. 